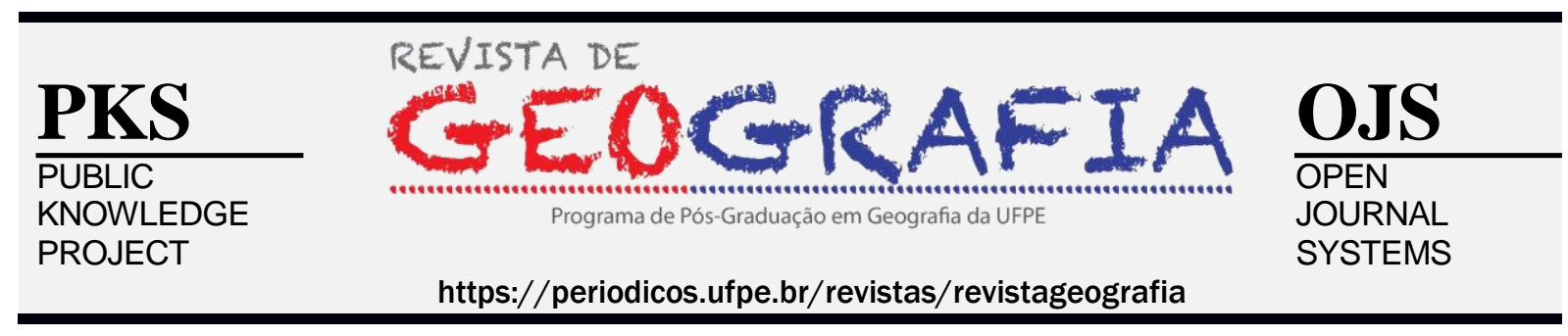

\title{
PARA ALÉM DE PARTIR OU PERMANECER: A MIGRAÇÃO QUILOMBOLA EM BUSCA DO TRABALHO ACESSÓRIO COMO ESTRATÉGIA DE R-EXISTÊNCIA NO TERRITÓRIO
}

\author{
Judson Jorge da Silva1 ${ }^{1}$, Cláudio Ubiratan Gonçalves² \\ IProfessor Assistente II do curso de Geografia da Universidade Estadual do Piauí - UESPI. E-mail: \\ judsonjorge@yahoo.com.br \\ ${ }_{2}^{2}$ Professor do Programa de Pós-graduação em Geografia da UFPE. E-mail: biragrario@gmail.com
}

Artigo recebido em 15/03/2020 e aceito em 17/03/2020

\begin{abstract}
RESUMO
Este trabalho analisa como as migrações sazonais de quilombolas da região do semiárido piauiense para o trabalho acessório têm sido utilizadas como estratégia de resistência para a permanência no território, a partir do exemplo dos moradores da comunidade Lagoa das Emas, pertencente ao território de quilombo Lagoas. Apresenta uma discussão a respeito da pluralidade de constituição dos territórios quilombolas, mostrando que não se trata de uma questão homogênea, tampouco linearmente ligada a redutos de escravos fugitivos no passado. Aponta que as migrações são resultado de um processo de desenvolvimento territorial desigual do trabalho, mas que, estrategicamente, são realizadas como forma de manutenção do grupo familiar no quilombo, configurando-se como uma espécie de resistência onde, dialeticamente, partir se configura como possibilidade de permanecer.

Palavras chave: Migração. Quilombola. Semiárido. Resistência. Território.
\end{abstract}

\section{BEYOND TO LEAVE OR TO STAY: THE QUILOMBOLA MIGRATION IN SEARCH OF ACCESSORY WORK AS A R-EXISTENCE STRATEGY IN THE TERRITORY}

\begin{abstract}
This research analyzes how the seasonal migrations of quilombolas from the semi - arid region in Piauí to accessory work have been used as a strategy of resistance to be able to stay in the territory, based on the example of residents of the community Lagoa das Emas, that belongs to the territory of quilombo Lagoas. It presents a discussion about the differences in the constitution of quilombola territories, showing that it is not a homogeneous matter, nor is it linearly linked to shelters for fugitive slaves in the past. It points out that migrations are the result of a process of unequal territorial development of work, but that are strategically carried out as a way of maintaining the family group in the quilombo, configuring itself as a kind of resistance where leaving becomes a possibility of staying. Keywords: Migration. Quilombola. Semi-arid. Resistance. Territory.
\end{abstract}




\section{INTRODUÇÃO}

O debate em torno das comunidades tradicionais, das terras tradicionalmente ocupadas, sobretudo por remanescentes quilombolas, é relativamente novo no âmbito da ciência geográfica e vem conquistando cada vez mais espaço desde a década de 1990. Nesse sentido, Anjos (2009, p.108), afirma que "tratar das comunidades quilombolas no contexto geográfico e histórico nacional significa se deparar com uma luta política e territorial atual e um processo de conhecimento científico ainda em construção."

No Piauí, onde segundo dados do Censo Demográfico do IBGE, em 2010 a população era de 3.118 .360 um total de $9,4 \%$ da população se declarou de cor ou raça preta e $64 \%$ se declaram de cor ou raça parda, atingindo um percentual de aproximadamente 2.288.876 habitantes, totalizando $73,9 \%$ da população como sendo composta por não brancos. "Ao findar a primeira década do século XXI, 174 Comunidades Quilombolas já haviam sido mapeadas no estado do Piauí" (LIMA, 2015, p. 241. No entanto, segundo o mesmo autor, até o ano de 2015 apenas 19 destas haviam sido tituladas pelo governo Federal. Entre as não tituladas está o território Quilombola Lagoas, o maior do país no tocante ao número de famílias que o compõem. Até o momento, 2019, a mesma se encontra sem titulação e sem uma previsão concreta de que isso aconteça, embora seja certificada pela Fundação Palmares (2014) e sua área se encontre já delimitada pelo INCRA. Neste sentido urge que seja debatida a questão negra no Estado, o que inclui os territórios de quilombo.

Ratts aponta que os cientistas sociais que realizam abordagens a respeito de grupos indígenas, negros e camponeses costumeiramente detêm-se a realizar estudos de caso ou etnografias e que, por outro lado "[...] os estudos tradicionais sobre migrações de camponeses e índios raramente se dedicam a avaliar o impacto desses fenômenos sobre agrupamentos étnicos e/ou rurais. Há poucos trabalhos sobre migrações negras no Brasil” (1999, p. 265-266).

Assim, compreendendo a relevância do tema, buscou-se aqui dialogar a respeito das relações ao redor da questão territorial e das dinâmicas migratórias sazonais envolvendo quilombolas do ambiente semiárido piauiense. Para isso, estabeleceu-se como orientação da discussão o seguinte questionamento: seria o ato de partir sazonalmente uma condição dialética para a permanência no lugar e, portanto, elemento essencial da identidade quilombola no contexto do semiárido, ou seria um fator de diluição de tal identidade? 
A relevância dessa discussão está, primeiramente, em investigar como nessa indissociável relação entre o quilombola e o seu território, paradoxalmente, a migração se apresenta como uma realidade. Conforme aponta Anjos (2009), existe um arraigado elo entre quilombolas e território. É em virtude desse intrínseco vínculo que se faz pertinente entender como tais relações se processam nas comunidades tradicionais. Em segundo lugar, porque nem mesmo a existência dessa forte identidade territorial é capaz de romper com a prática da migração temporária, principalmente para o trabalho no corte da cana-de-açúcar e construção civil, comum entre jovens e adultos quilombolas e outros camponeses.

Acreditamos que essas reflexões podem contribuir com o entendimento das diversas realidades apresentadas pelas comunidades tradicionais, bem como somar com as discussões a respeito do movimento quilombola e suas ações no Estado do Piauí. Pelo exposto, faz-se pertinente aprofundar o debate a respeito de tais questões.

\section{A PLURALIDADE DE CONSTITUIÇÃO DOS TERRITÓRIOS QUILOMBOLAS}

Segundo Carril, os quilombolas configuram-se como uma diferenciação no conjunto do campesinato. E é exatamente a singularidade desse grupo social que torna importante o entendimento dessa dinâmica, visando, a partir da interpretação das particularidades, compreender a multiplicidade étnica e cultural dos povos do campo. Buscando, assim, compreender a totalidade das realidades existentes no espaço agrário brasileiro.

[...],o quilombo rural traduz a sua luta pela terra e através da especificidade étnica, tanto vinculada ao direito territorial como calcada sobre a ancestralidade buscada na origem da conquista da terra. Logo, essa identificação demarca uma diferença no conjunto do campesinato. (2006, p. 169).

Tal compreensão somente será possível a partir do conhecimento e da caracterização dos diversos territórios existentes no campo, bem como dos sujeitos sociais que neles habitam e o modus vivendi praticado. Além, é claro, do reconhecimento das estratégias e atuação dos distintos movimentos de luta pela terra no país, como é o caso do Movimento Quilombola.

O primeiro passo no avanço desse debate é o de desconstruir a ideia reducionista de que os territórios quilombolas do tempo presente têm, necessariamente, uma linearidade com os territórios de resistência de negros do passado, ou seja, dos fugitivos da escravidão. Essa ideia, 
muito comum, por vezes é utilizada como um argumento para descaracterizar a luta do povo negro pelo direito a terra e ao território, enquanto espaço de vivência e trabalho.

Para os atores sociais que requerem as áreas dessas comunidades para a incorporação produtiva, sejam empresários, políticos ou cientistas associados ao capital, o fato de uma comunidade não ser descendente direta de um quilombo na concepção clássica ou que a área ocupada na atualidade não seja exatamente a de seus ancestrais, descaracterizaria o direito das comunidades atuais sobre a terra. Segundo Anjos (2009), essa visão assenta-se em uma interpretação restritiva e cristalizada do Artigo 68 das Disposições Transitórias na Constituição de 1988, que determina que "aos remanescentes das comunidades dos quilombos que estejam ocupando suas terras é reconhecida a propriedade definitiva, devendo o Estado emitir-lhes os títulos respectivos" (BRASIL, 2002, p. 159).

$\mathrm{O}$ ato de se aquilombar não se constitui de forma homogênea e paralisada no tempo. Quilombos, no censo comum, constituem redutos de escravizados fugitivos, formados por africanos e seus descendentes no longo período escravista brasileiro que se encerrou oficialmente em 1888 (RATTS, 1999, p. 264). No entanto, não se trata de grupos isolados, de população homogênea, ou constituídos, sempre, a partir de movimentos insurrecionais ou de rebelados (MORAES \& MATOS, 2013, p.5).

As pesquisas trouxeram à luz que a formação desses agrupamentos comunitários ocorreu também por outras vias como doações de terras, por abandono dos escravos pelos senhores e por terras doadas a santos (CARRIL, 2006, p.165). Uma ressalva, porém, deve ser feita nessa análise no que se refere a ideia de "abandono de escravos por senhores de terras". Sendo tratado como uma mercadoria que possuía alto valor comercial de troca, sobretudo após a proibição do tráfico negreiro, é improvável que senhores de terra abandonassem escravos, seja em virtude de problemas econômicos ou da seca no sertão. O mais provável seria a venda, para suprir os prejuízos financeiros.

Almeida, ao analisar os sistemas de uso comum na estrutura agrária brasileira, aponta também para a existência de terras de preto, terras de santo e terras de índio, formadas após a derrocada dos grandes sistemas produtivos de produtos primários dependentes do mercado internacional, sobretudo na passagem do século XIX. De acordo com esse autor,

As flutuações de preço dos produtos primários no mercado internacional provocaram sucessivas desorganizações no sistema produtivo das grandes explorações monocultoras. Antes mesmo da abolição da escravatura, que parece não servir de marco institucional que tenha favorecido esses sistemas de uso comum da terra, 
registram-se múltiplos casos de desmembramentos e desagregação de grandes propriedades fundiárias. Em termos econômicos, o resultado mais imediato desse processo de dissolução, que se intensificou no final do século XIX em regiões cujas grandes explorações não lograram introduzir inovações tecnológicas ou adotar agriculturas comerciais assentadas em novas relações de trabalho, constituiu no afrouxamento dos mecanismos repressores da força de trabalho e na formação de um campesinato, congregando segmentos de trabalhadores rurais que viviam escravizados ou imobilizados naquelas unidades produtivas (2009, p. 47).

No caso do Piauí, essa situação se desenvolveu a partir da decadência da pecuária ultra extensiva que, em seu auge, além do "gado em pé" negociava também subprodutos como charque e couro para abastecer os "mercados de Pernambuco e Bahia, mas eram mandados para os do Maranhão, Pará, Rio Grande do Norte, Paraíba, Minas Gerais e Rio de Janeiro (ALVES, 2003, p. 68), além do envio de charque para a Guiana Francesa e couro para a Inglaterra a partir do porto de Parnaíba (REGO, 2010).

No entanto, um amalgama de fatores que incluíram desde a rusticidade da pecuária praticada, passando pelo latifúndio e pela pouca diversificação produtiva que ocasionou uma dependência econômica local em relação a importação de manufaturas vindas de fora do Brasil ou das áreas com comércio dinâmico; somando-se à crise no setor canavieiro, que culminou no desmantelamento do sistema de plantations e transferiu para a área da mineração, em Minas Gerais, o centro dinâmico da colônia, o que provocou uma dilapidação da economia de áreas que outrora foram grandes compradoras da produção piauiense, houve um solapamento da economia pecuarista do Piauí. Quando a região da mineração passou a comprar gado dos pampas gaúchos, a economia piauiense entrou em colapso, refletido no reordenamento territorial e nas relações de trabalho.

Diante desse quadro econômico e de ordenamentos jurídicos que apontava para o fim do regime de escravidão no Brasil, como a lei do sexagenário e lei do ventre livre, Lima (2015) aponta para o estabelecimento de diversas estratégias para obtenção do acesso à terra no Piauí. Estas vão desde a formação dos territórios de remanescentes pelas vias do apossamento de terras em áreas não incorporadas pelo latifúndio, ou mesmo pela via da compra de terras realizada por ex-escravizados ou por seus descendentes. Cabe ainda apontar outras tantas estratégias, tais como a formação de comunidades com laços consanguíneos, os casamentos entre libertos e escravos, relações de compadrio e apadrinhamento dos filhos desses casais, que deram origem a moradores de condição, agregados, subordinados no seio do latifúndio.

Uma abordagem que não leve isso em consideração obscurece a tentativa de compreensão dos processos históricos de formação das comunidades tradicionais, pois geram 
uma lacuna que dificulta o entendimento da origem plural dos territórios quilombolas pelo país. Essa análise se torna ainda mais difícil em virtude do mito da não existência de trabalho escravo nas fazendas de gado, bem como na produção do algodão e nas lavouras de produção de gêneros alimentícios existentes no sertão ${ }^{1}$.

Conforme Versiani e Vergolino a ideia de que a utilização de mão-de-obra escrava não poderia coexistir com a atividade pecuária extensiva, no Sertão nordestino, tem raízes antigas na literatura, embora com racionalizações diferentes (2003, p.382). Segundo esses autores essa visão distorcida assenta-se em três teorias. A primeira delas, de que os negros, como raça, seriam inaptos para tal tipo de trabalho; em segundo lugar estaria o fato de que, na pecuária ultra extensiva os escravos ficariam muito longe dos olhos do senhor para serem vigiados. Uma terceira via de explicação seria o fato de que a mão de obra indígena seria mais barata do que a do cativo negro.

Essa interpretação se reforça ao passo que os estudos sobre a região Nordeste, com enfoque na produção territorial a partir das atividades produtivas, deixam de privilegiar o debate em torno do modo de produção e das relações de trabalho sob o qual se efetivaram, para se deter em nuances que não permitem um entendimento necessário a respeito desse processo. No caso do Piauí, por exemplo, ao tratar sobre colonização muitos estudos omitem a presença do trabalho escravo negro, enfocando na história oficial de colonizadores como Domingos Jorge Velho e Domingos Afonso Mafrense, que era ligado a Casa da Torre. Como eram fazendeiros absenteístas, emerge a figura do vaqueiro piauiense como sendo o trabalhador da pecuária. Já os indígenas, quando mencionados, são apresentados como meros coadjuvantes do processo, como uma espécie de entrave, uma rugosidade social que dificultava a implantação das fazendas de gado nas terras às margens dos rios piauienses.

Alves (2003), por exemplo, ao tratar sobre "as bases históricas da formação territorial piauiense" o faz a partir da visão da pecuária como carro chefe da colonização. Em sua abordagem os indígenas são mencionados apenas nas citações de referências históricas que contam sobre a "valentia" de certas etnias, e a respeito dos ataques que as mesmas efetuavam às fazendas de gado que buscavam se estabelecer na região. No texto não faz sequer menção as relações de trabalho envolvendo a mão de obra escrava no Piauí.

\footnotetext{
${ }^{1} \mathrm{O}$ termo sertão se refere a tradicional área nordestina em que se praticava a pecuária extensiva no período da colonização. Embora possuam definições e delimitações distintas, o sertão da pecuária ocupava boa parte da área que hoje se define como região do semiárido.
} 
Moraes aponta que a pecuária por muito tempo influenciou a forma de pensar a sociedade piauiense, chegando a constituir uma espécie de lugar retórico comum de tão entranhada nas narrativas mestras que tratassem sobre a sociedade e a história do Piauí.

\begin{abstract}
Como se sabe, desde o período colonial, até meados do século XIX, a pecuária extensiva foi, no Piauí, não apenas a principal fonte geradora da riqueza de fazendeiros e comerciantes e dos recursos necessários à manutenção e funcionamento das instituições públicas ao longo do período, mas também a base de uma forma de pensar a sociedade. Verdadeiro topus fundante na memória sócio-histórica do Piauí, mesmo quando se considera, segundo Santana (1964) e Medeiros (1996), que a pecuária piauiense não se constitui como um ciclo, por falta de dinamismo, essa premissa se faz presente (MORAES, 2006, p. 175).
\end{abstract}

No caso do semiárido piauiense, por muito tempo mantido como área de reserva de valor a partir da derrocada da atividade da pecuária, bem como do poder político das oligarquias, criou-se a possibilidade de fixação na terra de grupos de ex-escravos e seus descendentes. Seja como posseiros, seja mediante a compra de pequenas propriedades, seja a partir de um misto entre a compra e o apossamento, formaram-se territórios de ocupação tradicional baseados nos substratos pobres da população, principalmente nos povos negros e indígenas invisibilizados. Esses grupos passam a ocupar as áreas de gerais, as terras de ausentes, as terras de conjunto e quilombolas $^{2}$, ora subordinados a grande propriedade, ora formando territórios camponeses livres. É o caso do Território Quilombola Lagoas, que possui em sua origem a formação de

\footnotetext{
${ }^{2}$ Conforme dados apresentados na minuta do documento Marco da Política para Povos Indígenas (2018), em elaboração para suprir uma demanda surgida a partir do Projeto Piauí Pilares de Crescimento Inclusão Social, segundo aponta o Censo Demográfico do IBGE, em 2010 havia um total de 2307 pessoas se auto declaravam como população indígena no Estado do Piauí, distribuídas em 10 municípios. Já um levantamento da SESAPI - Secretaria de Estado de saúde do Piaú, mostra que no ano de 2016 esse número chegava a cerca de 6000 indígenas não aldeados, que se encontravam distribuídos em 36 municípios, autodeclarando-se como pertencentes as etnias Tabajara, Cariris, Gameleira e Guajajara. Ainda conforme o documento, em 2014 a FUNAI mencionava a existência de apenas três etnias indígenas no Estado, sendo elas os Tabajaras, os Cariris e os Codó-Cabeludo. Esse número de etnias se amplia na $2^{\circ}$ Assembleia Estadual dos Povos Indígenas, realizada em maio de 2018. Na assembleia, identificaram-se os seguintes povos indígenas: Tabajara/ Itacoatiara, Tabajara/Ypi e Tabajara/Tapuio, no município de Piripiri; Kariri, no município de Queimada Nova; Gamela, no município de Currais e Pirajá, no município de Santa Filomena. No entanto, ainda conforme o documento, entre estas etnias, apenas 31 famílias pertencentes ao povo Tabajaras da Aldeia Itacoatiara, localizada na zona urbana do município de Piripiri e 44 famílias Kariris, da aldeia Serra Grande, localizada na zona rural do município de Queimada Nova, estão reivindicando o reconhecimento pela Funai (SEPLAN, 2018).
} 
diversas comunidades a partir da fixação de grupos familiares, principalmente pelo sistema de compra de pequenas áreas e por apossamento de novas áreas no entorno, comumente chamada por eles de terras de “ausentes”. O Território Quilombola Lagoas é certificado pela fundação Palmares e aguarda a vários anos a sua titulação pelo INCRA, elemento essencial para a manutenção do território, ameaçado por projetos de mineração.

\title{
DIVISÃO TERRITORIAL DESIGUAL DO TRABALHO E MIGRAÇÃo CAMPONESA PARA O TRABALHO ACESSÓRIO
}

No semiárido, mesmo os territórios oficialmente reconhecidos, certificados e titulados pelo Estado estão alheios aos desafios estruturais e a pressões, tanto de caráter endógeno quanto exógenos. Entre as principais dificuldades vivenciadas está a da reprodução social e material de seus habitantes, pautadas na atividade agrícola tradicional de sequeiro e na criação animal para o consumo familiar. Em decorrência da baixa produtividade agropecuária, agravadas pelos períodos de estiagem e secas periódicas que ocorrem na região, a migração sazonal vem se apresentando historicamente como alternativa para a obtenção de renda por parte dos quilombolas.

Segundo Silva, sempre existiu influência das secas nas relações espaciais processadas nessa região. Conforme aponta,

\begin{abstract}
As secas no Sertão nordestino apareciam como um elemento de desordem no projeto de colonização. Havia um contraste significativo entre uma perspectiva sedentária de ocupação, com a fixação de povoamentos para exploração de riquezas, em relação às possibilidades de ocorrência das grandes secas. Para os povos nativos dos sertões, ao contrário, o nomadismo era uma das características de seu modo de vida, como afirma Medeiros Filhos (1988). Diante da natureza mutável do Sertão, das secas anuais, das longas estiagens e das enchentes nos anos mais chuvosos, os povos indígenas viviam em um regime nômade de vida, aproveitando os recursos disponíveis na natureza (SILVA, 2006, p.36).
\end{abstract}

Duas perspectivas de interação com o território se apresentam no relato acima. A primeira delas a do colonizador, que buscava a apropriação da terra para implantação de fazendas de gado em uma perspectiva patrimonialista e sedentária, de apossar, assentar-se e enriquecer. Já a segunda é a do nativo, que possuía uma relação de convivência com meio ambiente local, realizando migrações em busca das áreas que ofereciam recursos para coleta, caça e prática de uma agricultura em pequena escala quando assim fosse necessário. Uma 
perspectiva nômade que envolvia espaços entre sertão e litoral, serras úmidas e brejos, ou seja, toda a diversidade de natureza existente no que hoje se entende como território brasileiro.

Essa dinâmica de migração em terras secas não se trata de uma exclusividade do semiárido brasileiro. De acordo com Hillel (1991 apud SAFRIEL\&ADEEL, s/d, p.633), "typical to drylands are the diverse nomadic cultures that have historically played a key role in development of dryland farming systems ${ }^{3}$." Entretanto, é necessário considerar que, em nenhuma outra área semiárida do planeta a concentração fundiária é tão intensa como ocorre no Brasil, sendo essa a principal causa das desigualdades sociais existente nesse ambiente, que levam à migração temporária ou mesmo a expropriação permanente dos grupos frágeis, inclusive dos povos tradicionais.

Emergem aí duas dinâmicas distintas, a do nomadismo e a da migração forçada. A primeira, realizada pelos povos tradicionais, representado pelos indígenas, em virtude de sua unicidade orgânica com a própria natureza. Já a segunda, como resultado da indução pelo ritmo do capital, que gera a necessidade de mão de obra, instituindo a sua mobilidade.

No Brasil, esses movimentos populacionais que ocorrem desde o período colonial, ganham novas configurações a partir do desenvolvimento desigual do trabalho nas diferentes regiões do país, que provocou um intenso movimento de migração interna, sobretudo nos anos de 1950 a 1970, conhecido na literatura como êxodo rural, bem como os atuais processos de deslocamento marcados pela busca de trabalhos sazonais.

\begin{abstract}
Intensos fluxos de caráter rural urbano ocorreram nas décadas de 50 e 60 , representativos de um período marcado por crescente concentração fundiária e pela industrialização nos grandes centros urbanos do Sudeste Brasileiro. Estabeleceram-se migrações interestaduais de longa distância na década de 70 , especialmente a de nordestinos para o eixo Rio de Janeiro - São Paulo e a de sulistas para o Centro-Oeste e a Amazônia, responsáveis pela expansão e consolidação do mercado de trabalho a nível nacional. Multiplicaram-se as migrações de assalariados rurais temporários (volantes, boias-frias) especialmente para as colheitas da cana e da laranja, expressão do subemprego sazonal e das relações de trabalho informais gerados pela modernização capitalista no campo. Fomentaram-se os deslocamentos sucessivos de "barrageiros" para a construção de grandes obras de infra-estrutura [sic] energética ao longo das áreas de fronteira, seja internacional (Itaipu) ou nacional (Tucuruí, Balbina, etc) (BECKER, 2010, p. 321).
\end{abstract}

No que se refere aos fluxos de população rural do Piauí, os mesmos também existem desde o período colonial quando tangerinos conduziam as boiadas de gado local para a

\footnotetext{
3 São típicas das terras áridas diversas culturas nômades que, historicamente, desempenharam um papel fundamental no desenvolvimento de sistemas agrícolas em terras secas (tradução livre).
} 
comercialização em Olinda, Recife e Salvador (ALVES, 2003). Avançando no tempo, em meados de 1948 temos a significativa migração de piauienses e maranhenses para a região norte de Goiás em virtude da construção da estrada Transbrasiliana, que viria a fazer parte da rodovia Belém-Brasília, após iniciadas as obras da nova capital. Houve, inclusive, envolvimento desse grupo de migrantes que se converteu em posseiros naquela região, no emblemático conflito de Trombas e Formoso (MARTINS, 1981).

Em virtude dessas migrações ocorridas para a construção da estrada e da Capital, muitos piauienses fixaram residência no Centro Oeste. Por essa razão, Brasília se constitui como um dos principais destinos de migração efetuados por moradores da microrregião de São Raimundo Nonato na atualidade. Isso se explica pela existência de uma rede de solidariedade que é composta entre os que migraram anteriormente e os que migram na atualidade. Os que foram antes, primos, tios, vizinhos, fazem o elo entre o Piauí e o destino do migrante.

Essa situação não se restringe apenas ao Piauí, tampouco está circunscrita ao semiárido. Trata-se de um processo espacializado pelo Nordeste brasileiro, conforme evidenciam os estudos realizados nas décadas de 1980 e 1990 por Menezes, no sertão de Cajazeiras e agreste da Borborema, com pequenos proprietários, moradores e rendeiros.

\footnotetext{
Dada a precariedade das alternativas locais e existindo possibilidade de trabalho em condições comparativamente melhores em relação às locais, alguns membros da família, muitas vezes, migravam como estratégia de sobrevivência. O destino mais importante era São Paulo, mas havia também migração para Brasília. A migração para São Paulo remonta à década de 1930, conforme a memória das pessoas mais idosas. Os que já migraram funcionam como verdadeiro canal de informações, por meio das cartas e dos retornos constantes à origem. São os que estão em São Paulo que enviam o sinal verde para o momento exato da migração. Havia um inter-relacionamento entre Bonito de Santa Fé e São José de Piranhas com São Paulo muito mais intenso do que com outros municípios da própria microrregião, como Cajazeiras. (MENEZES, 2009, p. 275).
}

Em trabalho específico sobre a região de São Raimundo Nonato, Braga (2012), narra como se processam esses vínculos de solidariedade e de trocas entre emigrantes da zona rural de São Raimundo Nonato que se dirigem ao Bairro de São Miguel Paulista, leste do município de São Paulo. O autor destaca que a existência de um fluxo intenso não apenas de pessoas, mas também de mercadorias tanto do Piauí para São Paulo, quanto de São Paulo para o Piauí. O que se leva do Piauí são produtos que remetem à singularidade do lugar, como carne de bode, mel, queijo tipo requeijão e manteiga de garrafa. Já de lá chegam eletrodomésticos e outros produtos adquiridos com os salários economizados durante os meses de permanência. 
Já Gomes, em artigo que trata sobre o trabalho dos carregadores temporários piauienses na Companhia de Entrepostos e Armazéns Gerais do Estado de São Paulo CEAGESP, afirma que

\begin{abstract}
Em meio à diversidade de formas de trabalho que encontramos na CEAGESP, a que mais nos chamou atenção foi a figura do carregador, a atividade cuja expansão foi determinada principalmente pelas redes sociais. Identificamos que uma grande parte dos carregadores da CEAGESP é composta por migrantes oriundo do estado do Piauí. Em geral, eles residem na Grande São Paulo, sobretudo no município de Osasco. A partir do cadastro chegamos aos seguintes dados: $92 \%$ dos carregadores são oriundos do Nordeste do Brasil; sendo a maioria desse oriundo do Piauí, com participação de $67 \%$ do total de carregadores cadastrados, seguidos pelos cearenses cuja participação é de $15 \%$. Sendo que os municípios de origem dos cearenses são próximos dos municípios de origem dos piauienses. Constatando a força dessa rede social como instrumento de mobilidade do trabalho. (GOMES, 2009, p.4).
\end{abstract}

Situações como as acima narradas não são exclusividades apenas do sertão do Piauí. Parry Scott (2009) mostra como na zona canavieira e no agreste de Pernambuco, além do Maranhão, as migrações foram e continuam sendo usadas como estratégia de aproveitamento diversificado da mão de obra familiar, empregada no sentido de evitar o esfacelamento definitivo da unidade do grupo doméstico. Parte da família se emprega nos contextos de exploração local enquanto outra parte migra para São Paulo, com a finalidade de se assalariar e, se possível, comprar um pedaço de terra para que a família saia da condição de explorados.

O autor aponta que os próprios sujeitos, ao narrarem suas situações, faziam uso da expressão "meio do mundo", para designar os locais de migração e "cativeiro" ao referirem-se as condições de trabalho, moradia e habitação na qual se inseriam na zona canavieira de Pernambuco. Para Scott essa situação evidencia uma multiplicidade de contextos de poder, nos quais estão inseridos os camponeses, seja sob a égide do trabalho nas terras dos usineiros, por exemplo, seja no meio do mundo, local onde estão à disposição de outros empregadores, em busca de assalariamento.

Convém lembrar que, como nos explica Harvey,

A força de trabalho é uma mercadoria, mas as condições que governam sua mobilidade são muito especiais. É a única mercadoria que pode levar a si mesma para o mercado sem a ajuda de ninguém. Por isso, o termo "mobilidade do trabalho" ocupa uma posição especial no discurso econômico. Na teoria burguesa, e frequentemente no linguajar comum, ele se refere à liberdade do trabalhador de vender a sua força de trabalho quando, onde, por qualquer propósito e a quem lhe aprouver. Essa liberdade de contrato é fundamental para as concepções burguesas dos direitos humanos e das liberdades civis. Marx não nega a importância dessas liberdades positivas, mas insiste em que sejam vistas em relação a outro lado mais obscuro da coisa. O trabalhador é "livre em dois sentidos: de ser uma pessoa livre, que dispõe de sua força de trabalho 
como sua mercadoria, e de, por outro lado, ser alguém que não tem outra mercadoria para vender, livre e solto, carecendo absolutamente de todas as coisas necessárias à realização de sua força de trabalho". "Livre pelo processo da acumulação primitiva do controle sobre os meios de produção (incluindo o acesso à terra), a maioria dos trabalhadores não tem opção a não ser vender sua força de trabalho ao capitalista para poder sobreviver (2013, p. 485).

Em virtude de processos envoltos nessa lógica, atuando sobre povos do campo, surgiram no Brasil movimentos sociais de luta pela terra e permanência na mesma, a exemplo do Movimento dos Sem-Terra (MST) e do próprio Movimento Quilombola. Já no semiárido essa discussão volta-se, principalmente, para as questões de convivência com esse ambiente a partir das práticas e saberes tradicionais, bem como a partir da conquista de políticas públicas que respeitem as dinâmicas socioambientais locais e permitam melhorias nas condições de vida dos habitantes.

É a contramobilidade emergindo como expressão do direito de "não migrar", ou de permanecer no espaço de origem; é a luta em defesa do livre arbítrio quanto ao espaço a ocupar, a cultura a preservar. É o singular tentando manter o seu lugar no espaço econômico (BECKER, 2010, p. 322).

Ao mesmo instante é preciso considerar que, conforme afirma Woortmann

A migração de camponeses não é apenas uma consequência da inviabilização de suas condições de existência, mas é parte integrante de suas próprias práticas de reprodução. Migrar, de fato, pode ser condição para a permanência camponesa (1990, p.35 apud Menezes, 2009, p.271).

\section{A MIGRAÇÃO SAZONAL NO QUILOMBO LAGOAS}

O território do quilombo Lagoas possui uma área total de 62 mil hectares, na qual estão inseridas 118 comunidades, agrupadas em 12 núcleos. Essas comunidades encontram-se distribuídas entre seis municípios, sendo os de Bonfim do Piauí, Dirceu Arcoverde, Fartura do Piauí, São Lourenço do Piauí, São Raimundo Nonato e Várzea Branca, aglutinando em torno de 1.498 famílias, que totalizam aproximadamente 5.128 pessoas, segundo dados do INCRA PI (BRASIL, 2011). Trata-se, portanto, do maior território quilombola do Brasil, no tocante a quantidade de comunidades que o integra (MATOS \& RODRIGUES, 2010). (Figura 1). 
Figura 1 - Localização do Território Lagoas no Piauí/Brasil

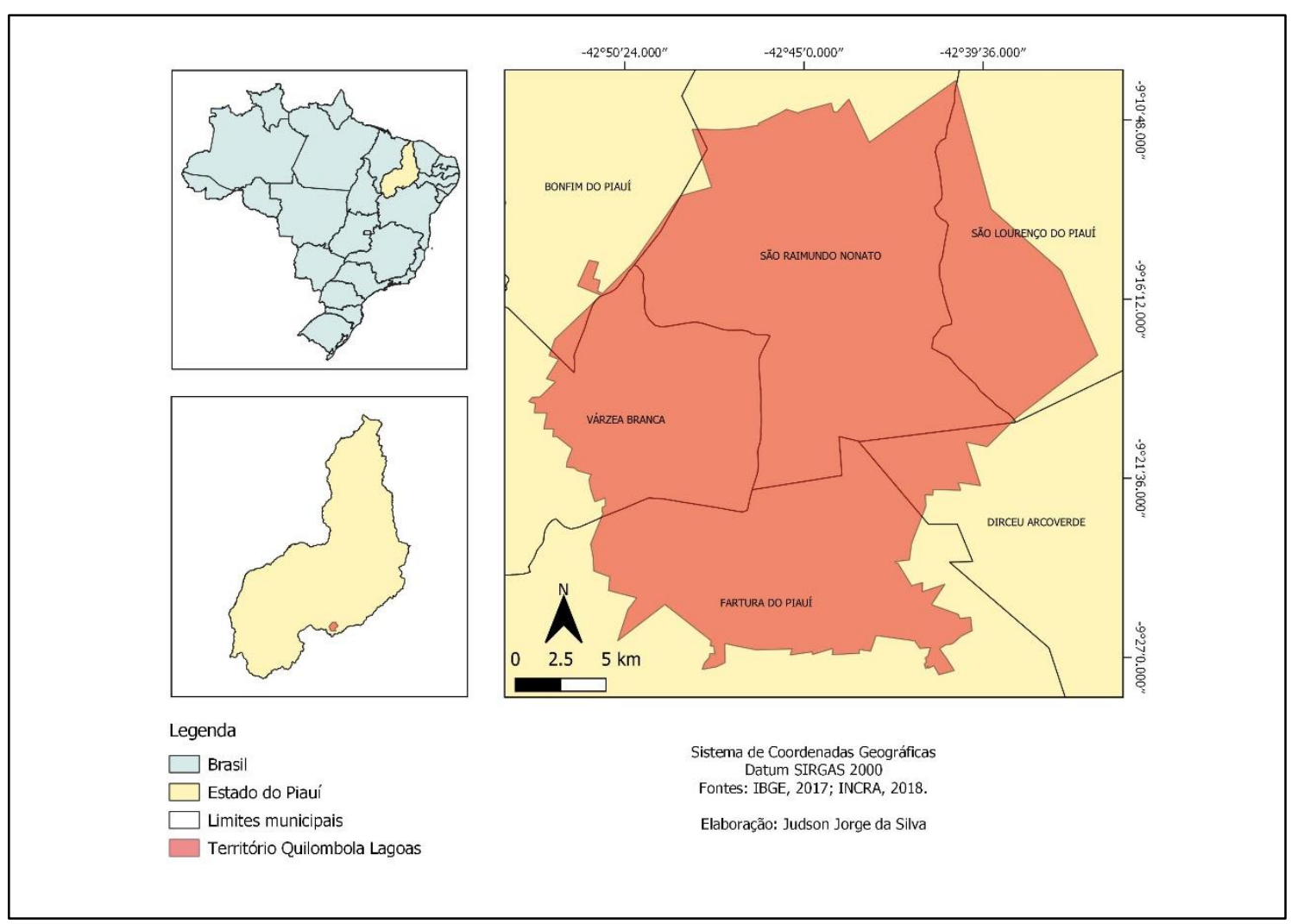

Autor: Judson Jorge da Silva

\section{Segundo Matos e Moraes,}

[...] os diversos grupos organizam-se espacialmente conforme a localização das terras adquiridas por pais, avós/avós e bisavôs/bisavós. Para a constituição desses grupos, predominou o parentesco consanguíneo, embora não exclusivamente. No que tange à organização do parentesco, o ponto de partida foi a Fazenda São Victor, local narrado como de ascendentes escravizados dos sujeitos da pesquisa. As comunidades em que se localizam os descendentes são: Boi Morto, Lagoa das Pombas, Baixão do Boi, Retiro, Lagoa do Moisés, Lagoa das Emas; e também as localidades próximas: Lagoa dos Martins, Lagoa do Mel e Lagoa do Jacaré. Assim se conforma essa grande família e grande parte dela localiza-se em Lagoa do Calango e Lagoa dos Prazeres. [...] Os agrupamentos Lagoa das Emas, Lagoa dos Martins, Boi Morto, Lagoa do Mel, Lagoa do Jacaré, Lagoa do Moisés, Baixão do Boi e Retiro interligam-se por um sistema de parentesco. Os laços deste sistema foram relatados oralmente por anciãos e anciãs de Lagoa das Emas, Lagoa do Moisés, Retiro, Baixão do Boi e Boi Morto (MATOS; MORAES, 2015, p. 209-210).

Os quilombolas de Lagoas migram anualmente em busca do trabalho acessório. Entre as comunidades do território, a migração se dá com maior ênfase na comunidade Lagoa das Emas. Composta por 33 famílias, de acordo com Braga e Silva (2016), em praticamente todas elas existe pelo menos um membro que migra sazonalmente. 
A própria origem da comunidade Lagoa das Emas se funde com a questão das migrações.

\begin{abstract}
O histórico da origem da comunidade foi identificado a partir da história oral, através dos relatos do Seu Raimundo Derré. É datada do ano de 1953, com a chegada da família Marques, em terras antes pertencentes ao Fazendeiro Baldoíno. O filho mais velho da família foi o responsável pela compra do local. O dinheiro empregado na compra veio do trabalho na construção civil adquirido na região sudeste. [...]. Antes, a família morava numa fazenda no povoado Lagoinha dos Macários. Tempos depois, seu Raimundo Derré voltou a morar na propriedade do fazendeiro Baldoíno para que ficasse mais próximo da fazenda na qual trabalhou por vinte e cinco anos, e a quem se dedicou desde os treze anos de idade. Mais tarde, após a morte do fazendeiro Baldoíno, a filha de nome Sinhá que havia herdado as terras do pai, o vendeu uns 30 hectares em torno da casa que já havia levantado a pedido do fazendeiro. Outras pessoas da comunidade Emas também compraram mais uns 130 hectares, e que somadas à primeira propriedade adquirida em 1953, formam hoje as terras nas quais os remanescentes de quilombolas vivem (BRAGA, 2016, p.22).
\end{abstract}

Após a fixação desse grupo, iniciou-se um movimento cíclico, que vem sendo reproduzido pelos jovens do sexo masculino, desde meados da década de 1970. Nesse período, segundo Braga (2016), as migrações passaram a ocorrer para o Maranhão e Tocantins, destino que hoje já não é mais buscado por membros locais. Atualmente, os destinos mais comuns buscado pelos migrantes são os Estados de Mato Grosso, São Paulo, Minas Gerais, Goiás, Rio de Janeiro e Brasília. Nesses locais, os postos de trabalho ocupados geralmente são nos setores da construção civil e no corte de cana-de-açúcar, atividades que requerem pouca qualificação.

O período de permanência nesses Estados varia entre três a oito meses, que normalmente coincide com o período mais intenso de estiagem no semiárido, que vai de maio a setembro. A partir do mês de setembro os trabalhadores retornam para a comunidade e reassumem os trabalhos com a pequena pecuária de caprinos e suínos, além da agricultura. Ainda no mês de setembro iniciam a brocagem, seguida da coivara e das capinas nas áreas que serão cultivadas, caso a quadra chuvosa seja satisfatória.

No entanto, desde o ano de 2009 a região enfrenta uma seca prolongada, que tem inviabilizado a agricultura e encarecido a manutenção dos rebanhos de caprinos, pois muitas vezes a água e a ração precisam ser compradas. Essa situação reforça a necessidade de busca pelo trabalho em outras regiões, de modo a viabilizar o sustento da família e a continuação com as práticas produtivas que desempenham no território do quilombo.

Segundo dados do Relatório Antropológico de Identificação e Delimitação do Território Quilombo Lagoas, 
Na região semiárida os povos quilombolas e sertanejos que têm raízes no campo, diante de um modelo econômico excludente, são "naturalmente" conduzidos para um modo de vida econômica que não apresenta alternativas sustentáveis de manutenção digna em seus espaços locais. Às mulheres fica a função de cuidar dos filhos, casa, garantir o alimento no dia-a-dia, o cuidado com a roça e animais. Já os homens, em geral, arrimos de família, precisam sustentar a casa com trabalho na roça ou com a migração para a realização de trabalhos precários em outras regiões do país (MATOS \& RODRIGUES, 2010, p.63).

Pelo exposto, é possível compreender o papel desempenhado pelo trabalho acessório no sentido de garantir a manutenção no núcleo familiar. Em decorrência de uma produção voltada apenas para o autoconsumo, um membro da família recorre à migração temporária como forma de obter renda. Ao retornar, reassume suas atividades tradicionais na comunidade. Essa dinâmica possibilita que a família não seja obrigada a migrar definitivamente para um grande centro. Nesse sentido, partir temporariamente em busca de trabalho não agrícola é condição essencial para conseguir permanecer no território quilombola, trata-se, portanto de uma estratégia de resistência e r-existência que impede a migração definitiva da família.

\section{CONSIDERAÇÕES FINAIS}

Buscou-se aqui discutir como as migrações sazonais são praticadas por membros de comunidades tradicionais, que partem em busca do trabalho acessório em outras regiões do país. De modo específico, esse olhar se voltou para a dinâmica envolvendo quilombolas da região semiárida.

No sentido de contextualizarmos o debate, tratamos a respeito da formação dos territórios quilombolas, de modo a desconstruir uma visão reducionista sobre estes, como se obrigatoriamente fossem algo homogêneo e com uma ligação linear aos territórios de resistência do passado, formados a partir de escravos fugitivos no período da escravidão. Nossa análise visa desconstruir os argumentos que colocam em xeque a autenticidade das comunidades que se auto reconhecem como remanescentes de quilombo na atualidade

Ao tratarmos sobre os processos migratórios, fizemos um resgate histórico no sentido de mostrar que, em decorrência da dinâmica natural do ambiente semiárido, os povos autóctones já empreendiam migrações nos períodos de estiagem, devido a um nomadismo pautado na busca de condições naturais favoráveis a sobrevivência. Dinâmica essa que foi interrompida pela perspectiva patrimonialista e sedentária do colonizador. Tendo sido 
inaugurada um uma nova perspectiva no caráter dos movimentos populacionais, pautado agora na divisão do trabalho.

Apontou-se a necessidade de analisar o fenômeno das migrações a partir da lógica do processo de desenvolvimento territorial desigual do trabalho no Brasil. Com seu intenso processo de industrialização e pelo crescimento de setores como o da construção civil, da possibilidade de exercer atividades informais e subempregos nas grandes cidades, sobretudo em São Paulo, além da existência de trabalho assalariado em segmentos da agricultura paulista, como o setor sucroalcooleiro, essa região capitaneia os fluxos migratórios de grande parte da mão de obra nordestina, inclusive os provenientes das comunidades tradicionais, como as quilombolas, localizadas no semiárido do piauiense.

Para Peek (1978, p. 2 apud BECKER, 2010, p.333) existem relações entre esse tipo de migrações e o processo de mudança agrária nos países subdesenvolvidos. Em sua visão, na agricultura latino-americana estaria ocorrendo uma transição da produção não capitalista para a capitalista. Assim, a emigração rural seria considerada como sendo o resultado da proletarização do trabalho que acompanha essa transição.

No entanto, contestando tanto a vertente teórica que interpreta o campesinato como um resíduo social a ser expurgado do campo brasileiro pela penetração do capitalismo no campo, bem como a que apresenta a migração como sendo o resultado inexorável da definitiva proletarização, e entendendo os quilombolas como um tipo de camponês envolto por um universo de especificidades históricas, sociais, culturais e étnica, compreendemos que, em virtude do processo de desenvolvimento territorial desigual do trabalho nas diferentes regiões do país, bem como das dificuldades de sobrevivência a partir das práticas da agricultura tradicional em uma área inserida em pleno ambiente semiárido, desassistida de políticas sociais e de produção adequadas a dinâmica ambiental e cultural local, o processo de migração de quilombolas para trabalhar temporariamente como assalariados nas regiões do Sudeste e Centro-oeste do Brasil, em vez de decretar o "fim" desses territórios, configura-se como possibilidade de resistência, na qual, dialeticamente, o impelido ato de partir configura-se, também, de modo contraditório e combinado, como a possibilidade de permanecer no seu lugar de origem e defendê-lo e não ser expulso definitivamente. Portanto, esse processo não decreta o ocaso desses territórios negros, mas sim os ressignificam e os reafirmam a partir de identidades reelaboradas e formas complexas de r-existências. 


\section{REFERÊNCIAS}

ALMEIDA, A.W.B. Terras de Preto, Terras de Santo, Terras de Índio: Uso Comum e Conflito.In:GODOI, E. P; MENEZES, M.A de; MARIN, R.A. (Orgs.). Diversidade do Campesinato: expressões e categorias. São Paulo: Editora da UNESP, v.02, 2009.

ALVES, V. E. L. As bases históricas da formação territorial piauiense. Geosul, $\begin{array}{llllllll}\text { Florianópolis, } & \text { v. } & 18, & \text { n. } & 36, & \text { p } & 55-76, & \text { jul./dez. }\end{array}$ . $<$ https://periodicos.ufsc.br/index.php/geosul/article/download/.../12450>. Acesso em julho de 2015

ANJOS, R.S.A. Quilombos, Geografia Africana, Cartografia Étnica, Territórios Tradicionais. Brasília:Mapas Editora \& Consultoria Ltda, 2009.

BECKER, O.M.S. Mobilidade Espacial da População: Conceitos, Tipologia, Contextos. In: CASTRO, I.E.de; GOMES, P.C.da G.; CORRÊA, R.L. (orgs.). Explorações Geográficas.4.Ed.Rio de Janeiro: Bertrand Brasil, 2010.

BRAGA, Juçara da Silva; Silva, Judson Jorge da. Migração Sazonal dos Quilombolas da Comunidade Lagoa das Emas, integrante do Quilombo Lagoas, em São Raimundo Nonato - PI. XV SEMINÁRIO DE INICIAÇÃO CIENTÍFICA DA UESPI. XV SIC, de 23 a 25 de novembro de 2016. Teresina: Livro de resumos, 2016.

BRAGA, Juçara da Silva Migração temporária na Comunidade Quilombola Lagoa Das Emas. Monografia (Licenciatura Plena em Geografia: Ensino Superior). 44p. UESPI, 2016.

BRASIL. Senado. Constituição (1988). Constituição da República Federativa do Brasil. Promulgada em 5 de outubro de 1988. Brasília: Senado Federal, Subsecretaria de Edições Técnicas, 2002.

. Piauí terá a maior comunidade quilombola do País, com mais de mil famílias. Net, Brasília, DF, jan, 2011. Governo. Disponível em: <http://www.brasil.gov.br/governo/2011/01/piaui-tera-a-maior-comunidade-quilombola-dopais-com-mais-de-mil-familias>. Acesso: 08 de abril de 2014. 
BRAGA, A. M da C. O Que Se Leva, O Que Se Traz: Fluxos Migratórios e Fluxos de Mercadorias entre o Interior do Piauí e a Cidade de São Paulo. In: TEIXEIRA, P.E, BRAGA; A.M. da C; BAENINGER, R. (Orgs.). Migrações : implicações passadas, presentes e futuras. Marília: Oficina Universitária; São Paulo: Cultura Acadêmica, 2012.

CARRIL, Lourdes de Fátima Bezerra. Quilombo, Território e Geografia. Revista AGRÁRIA, n 3, São Paulo, 2006. p. 156-171.

FARIA, Ana Tereza Dutra Pena de. Comunidade quilombola Lagoas. Belo Horizonte: FAFICH, 2016.

FUNDAÇÃO PALMARES. Quadro geral de comunidades remanescentes de quilombos (CRQs). Net, Brasília, DF. Disponível em: <http://www.palmares.gov.br/wpcontent/uploads/2016/06/QUADRO-RESUMO.pdf>. Acesso: 08 set 2016.

GOMES, S. de C. Os Trabalhadores temporários Piauienses da CEAGESP. Anais do XIX Encontro Nacional de Geografia Agrária, 2009. Disponível em: $<$ http://www.nemo.uem.br/artigos/carregadores_temporarios_ceagesp_sueli_castro_gomes.pd f>. Acesso em 01 de julho de 2015.

HARVEY, D. Os Limites do Capital. São Paulo: Boitempo, 2013.

LIMA, Solimar Oliveira. Sertão Quilombola: comunidades negras rurais no Piauí. In: LIMA, S.O; Fiabani, A. Sertão Quilombola: comunidades negras rurais no Piauí. Teresina: EDUFIPI, 2015.

MARTINS, José de Souza. Os camponeses e a política no Brasil. $4^{\circ}$ Ed. Petrópolis: Vozes, 1990.

MATOS, Simone O. \& RODRIGUES, Maria Sueli. Relatório Antropológico de identificação e Delimitação do Território Quilombo Lagoas. Piauí, São Raimundo Nonato: 2010. 
MATOS, S. O; MORAES, M.D.C. Territorialidade Quilombola em Lagoas (PI): memória dos "tempos do cativeiro" e questões de titulação. In: LIMA, S.O; Fiabani, A. Sertão Quilombola: comunidades negras rurais no Piauí. Teresina: EDUFIPI, 2015

MENEZES, Russel Parry. Migrações: Uma experiência histórica do campesinato do Nordeste. In:GODOI, E. P; MENEZES, M.A de; MARIN, R.A. (Orgs.). Diversidade do Campesinato: expressões e categorias. São Paulo: Editora da UNESP, v.02, 2009.

MORAES, Maria Dione Carvalho de \& MATOS, Simone de Oliveira.Territorialidade Quilombola: atores, processos, e sentidos populações negras rurais e ordenamento territorial em Lagoas, Piauí, NE do Brasil. Actz Científica XXIX Congresso de la Asociación Latinoamericana de Sociologia 2013, disponível em:<http://actacientifica.servicioit.cl/biblioteca/gt/GT7/GT7_CarvalhodeMoraes_OliveiraMat os.pdf >. Acesso em: 17 de setembro de 2015.

MORAES, M.D.C de. Do destino pastoril à vocação agrícola: modernização agrícola dos cerrados e inflexões discursivas nas narrativas mestras do Piauí. In: ELIAS, D. \& PEQUENO, R. Difusão do agronegócio e novas dinâmicas socioespaciais. Fortaleza: Banco do Nordeste, 2006.

OLIVEIRA, Ariovaldo Umbelino. A Geografia das Lutas no Campo. 6 Ed. São Paulo: Contexto, 1994.

A Geografia Agrária e as Transformações Territoriais recentes no campo Brasileiro. In: CARLOS, A.F.A. (org.). Novos Caminhos da Geografia. 6 Ed. São Paulo: Contexto, 2012.

RATTS, Alex. Traços étnicos: espacialidades e culturas negras e indígenas. Fortaleza: Museu do Ceará. 2009. 
Entre quilombos no litoral, no sertão e na Amazônia: memórias de negros migrantes. In: HEIDEMANN, H.D. \& SILVA, S. A. (Orgs.). Simpósio Internacional Migração: nação, lugar e dinâmicas territoriais. São Paulo: Associação Editorial Humanitas, 2007.

REGO, Junia Motta Antinaccio Napoleão do. Dos sertões aos mares: história do comércio e dos comerciantes de Parnaíba (1700-1950). Tese (Doutorado)- Programa de Pós-Graduação em História da Universidade Federal Fluminense, Niterói, 2010.

SAFRIEL,Uriel\& ADEEL, Zafar. Dryland Systems.Net. Disponível em: <http://www.unep.org/maweb/en/index.aspx>. Acesso em: 27 set. 2014

SANTOS, M. A Natureza do Espaço. Técnica e Tempo. Razão e Emoção. 4.ed. São Paulo: Editora da Universidade de São Paulo, 2004.

SEPLAN - Secretaria de Planejamento do Piauí. Marco da Política para Povos Indígenas. Projeto Piauí Pilares de Crescimento e Inclusão Social. Teresina: 2018. Disponível em: <http://www.seplan.pi.gov.br/marco.pdf>. Acesso em março de 2020.

SILVA. Roberto Marinho Alves da. Entre o Combate à Seca e a Convivência com o Semiárido: Transições paradigmáticas e sustentabilidade do desenvolvimento. 2006. 298 f. Tese (Doutorado) - Universidade de Brasília, Brasília, 2006.

SCOOT, Russel Parry. Famílias camponesas, migrações e contextos de poder no Nordeste brasileiro: entre o "cativeiro" e o "meio do mundo". In: GODOI, E. P; MENEZES, M.A de; MARIN, R.A. (Orgs.). Diversidade do Campesinato: expressões e categorias. São Paulo: Editora da UNESP, v.02, 2009.

VERSIANI, Flávio Rabelo \& VERGOLINO, José Raimundo Oliveira. Posse de Escravos e Estrutura da Riqueza no Agreste e Sertão de Pernambuco: 1777-1887. Est. Econ., São Paulo, v. 33, n. 2, p. 353-393, abr-jun. $2003 . \quad<$ http://www.revistas.usp.br/ee/article/view/35793/38509>. Acesso em 10 de agosto de 2013 